\title{
La palabra de los otros: maestras denunciadas en las escuelas primarias fiscales durante la segunda mitad de la década del cuarenta*
}

\author{
The Word of Others: Women Teachers Reported in the National Elementary \\ Schools during the Second Half of the 1940s
}

GABRIELA VERÓNICA FERREYRA

Resumen

Este artículo explora los alcances y las limitaciones de los discursos escolares moralistas que contribuyeron a vigilar y regular el comportamiento de las maestras noveles durante la segunda parte de la década de 1940. Desde una perspectiva de género, se revisa la red de significaciones que conformaban la categoría "maestras" desde la mirada del Estado y de la sociedad civil, y se problematiza la referencia al "magisterio" como un bloque homogéneo de experiencia histórica común. El corpus documental está compuesto por una selección de sumarios administrativos pertenecientes al fondo del Consejo Nacional de Educación (CNE).

Palabras clave

Género; Maestras; Denuncia; Testimonios; Comunidad Escolar

\begin{abstract}
This article explores the scope and limitations of moralistic school discourses that contributed to monitor and regulate the behavior of novice female teachers during the second half of the 1940s. From a gender perspective, this work reviews the network of meanings that made up the category "female teachers" from the perspective of the State and civil society, and questions the reference to "the teachers" as a homogeneous block of common historical experience. The documentary corpus is composed of a selection of administrative belonging to the collection of the National Education Council.
\end{abstract}

Keywords

Gender; Female Teachers; Report; Testimonials; School Community

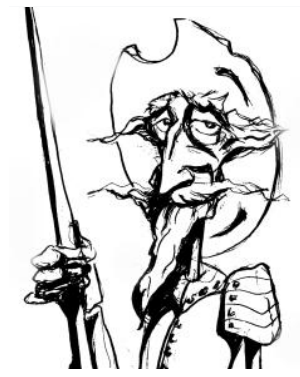

Recibido con pedido de publicación el 10 de enero de 2021

Aceptado para su publicación el 1 de abril de 2021

Versión definitiva recibida el 15 de mayo de 2021

https://doi.org/10.35305/prohistoria.vi36.1519

Gabriela Verónica Ferreyra, Universidad Nacional de Tres de Febrero, Buenos Aires, Argentina; e-mail: gferreyra@untref.edu.ar

* Agradezco los comentarios y las sugerencias recibidas por parte de los evaluadores.

Esta obra se publica bajo licencia Creative Commons. Atribución-NoComercial-CompartirIgual 4.0 Internacional

Ferreyra, G. La palabra de los otros: maestras denunciadas en las escuelas primarias fiscales durante la segunda mitad de la década del cuarenta. Prohistoria, Año XXIV, 36, dic. 2021, 1-17. 


\section{Introducción}

Al cerrar el ciclo lectivo de 1946, tres maestras jóvenes se presentaron en la sede de la Inspección Seccional Sexta de Viedma, Río Negro, para exponer un reclamo en contra de su director. Solicitaban la rectificación del "injusto concepto" profesional que habían recibido. En uno de los párrafos de la nota que acompañó el pedido, una de las docentes agregó “En varias oportunidades he sido tratada en forma grosera [...] De la misma manera he sido molestada varias veces por insinuaciones al margen de toda moral". ${ }^{1}$

A comienzos del siglo XX, la marcha hacia el orden y el progreso reveló una mayoritaria composición femenina en las filas del magisterio. Obedientes, cariñosas, pacientes, dispuestas a percibir baja remuneración, el proyecto pedagógico del naciente Estado argentino tomó esas cualidades "naturales" (Lionetti, 2007; Morgade, 1997), las adaptó al discurso heteronormativo sobre el cuerpo y el género, e instaló una concepción política sobre el "ser y parecer" de la maestra mujer.

El objetivo de este artículo es explorar los alcances y las limitaciones de los discursos escolares que contribuyeron a vigilar y regular el comportamiento de las maestras noveles durante la segunda parte de la década de 1940. Desde una perspectiva de género, que sugiere que las relaciones entre los sexos son prioritarios en la organización social, que la identidad femenina y masculina están determinadas culturalmente y que las diferencias entre los sexos constituyen estructuras sociales jerárquicas (Scott, 2008: 46), se analiza la red de significaciones de la categoría "maestras" construida por el Estado, la apropiación por parte de los y las integrantes de la comunidad educativa, y la referencia al "magisterio" como un bloque homogéneo de experiencia histórica común.

El corpus documental está formado por una selección de expedientes tramitados por los inspectores del Consejo Nacional de Educación (CNE), órgano que administraba la educación primaria en las escuelas de la Capital Federal, de las Provincias y de los Territorios. Del conjunto, se tomaron las carpetas con sumarios fechados en 1948 y compuestos por declaraciones testimoniales y diferentes pruebas que abarcaban un período mayor, de 1946 a 1949. ${ }^{2}$

\footnotetext{
${ }^{1}$ Archivo Intermedio de la Nación (AIN). Consejo Nacional de Educación (CNE), expediente núm. 10.705, Río Negro, 1948.

${ }^{2}$ Durante esos años el gobierno de Perón aplicó a nivel nacional la primera reforma educativa. En el plano administrativo, mantuvo la intervención del Consejo Nacional de Educación hasta 1949, cuando fue disuelto. En el plano pedagógico, promulgó novedades en la organización de los contenidos y promovió la intervención de la escuela en la vida social de la comunidad a
} 
El trabajo está organizado en dos secciones. La primera parte describe las características y problemáticas que aborda el conjunto de investigaciones sumariales seleccionadas. La segunda reconstruye un caso puntual que visibiliza las implicancias del "deber ser" de las maestras en la vida cotidiana de la escuela y fuera de ella, en los espacios públicos de esparcimiento. En este apartado se presta especial atención a los testimonios de las educacionistas, de los vecinos, de las autoridades de la comunidad, del director y del inspector. Estas narrativas funcionan como punto de referencia alrededor del cual es posible reconocer las nociones de feminidad imbricadas en los comportamientos personales y colectivos de la época.

\section{Las evidencias: el archivo que habla de ellas y las hace hablar}

Para estudiar el comportamiento público de las mujeres maestras, la historiografía se ha concentrado en diferentes fuentes documentales, autobiografías, escritos de viajes, diarios íntimos, correspondencia, libros de texto y notas publicadas en revistas. Un grupo de trabajos analiza las trayectorias de educacionistas que se vincularon "al feminismo y al gremialismo docente, vivieron aventuras y enfrentaron peligros, inventaron técnicas pedagógicas, tradujeron libros y [...] recibieron homenajes de las comunidades locales y de los gobiernos" (Yannoulas, 1996: 186). Desde esa perspectiva, se abordan las redes sociales y profesionales compartidas por Olga y Leticia Cossettini (Caldo y Fernández, 2010); las representaciones sobre el amor romántico en los escritos de Herminia Brumana y Angélica Mendoza (Becerra, 2019); y el pensamiento pedagógico y acción partidaria de Florencia Fossatti (Alvarado, 2017).

El segundo grupo, desanda el proceso de construcción de la identidad de las docentes, la feminización del magisterio, los argumentos políticos que lo legitimaron y los factores que intervinieron en la construcción simbólica de la ocupación del espacio público, desde diferentes escalas de análisis, regionales y locales (Yannoulas, 1996; Morgade, 1997; Lionetti, 2007; Billorou, 2016). En esta línea, otras investigaciones prestan atención a las prácticas discursivas y los mecanismos de intervención del Estado ante el comportamiento del personal docente femenino, el rol de los inspectores escolares y la reglamentación que se aplicó durante la primera mitad del siglo XX (Fiorucci, 2013; Caldo, 2019; Cammarota, 2020). En diálogo con la propuesta de estos autores y autoras, en este artículo se retoma el archivo trabajado para interrogarlo acerca de las

través de la vinculación afectiva y social del personal directivo y docente con los vecinos. A nivel normativo, los nuevos lineamientos no incluyeron modificaciones en el Digesto Escolar (1937) y en el Reglamento de Sumarios (1925). 
reacciones o repercusiones que generaron, en el ámbito social y escolar, aquellas mujeres que con sus gestos, actitudes y valores, transgredieron el modelo hegemónico.

Del total de expedientes, que abarca el período 1882-1957 y trata cuestiones relacionadas con el funcionamiento del sistema de educación primaria, la asignación de partidas, apertura de escuelas, pedidos de traslados y jubilación de personal, se revisaron los sumarios iniciados por los inspectores de las escuelas fiscales de Provincias y Territorios del CNE, ingresados por mesa de entrada en 1948 y cuyo asunto se titula con el nombre "denuncia". ${ }^{3}$ Cada uno está compuesto por una serie de carpetas con notas, declaraciones de los testigos, informes de observación pedagógica, copias de reuniones de personal, avisos, actas, datos sobre el desempeño profesional de los denunciados y un dictamen. En algunos casos, la carpeta incluye la foja u hoja de concepto del o la docente. En esta planilla, el director o directora redactaba una valoración individual, el concepto y la reputación que tenía en el vecindario, destacaba las iniciativas y ponderaba la colaboración en actos, fiestas o actividades extraescolares (Méndez y Zampa, 2019: 117-118). El ítem 16 de la Hoja de Concepto, "Cualidades dignas de mención (Siempre en forma concreta; caracteres de cordialidad, tolerancia, respeto, aliño, propiedad de lenguaje, espíritu de colaboración, cortesía, reputación, etc.)", funcionaba como guía exacta de un comportamiento que se pretendía universal, incuestionable y neutro.

Estos documentos, generados por la burocracia, posibilitan un acercamiento a las repercusiones que tenían en la vida cotidiana algunas de las condiciones que establecía el Estado para el ejercicio de la docencia. Si bien las palabras y expresiones no eran espontáneas, porque estaban limitadas por las preguntas que interesaban al inspector sumariante (Fiorucci, 2013), en ellas se identifica la concepción de un estado "natural" del "ser docente". Cada carpeta transmite cierta decepción, enojo o fastidio por el incumplimiento de los códigos morales de la "sagrada misión". ${ }^{4}$

\footnotetext{
${ }^{3}$ Según el Reglamento de Sumarios (1925), en las Provincias y Territorios los sumarios eran instruidos por el Visitador, el Inspector Viajero, el Inspector Seccional, el Inspector Sumariante o funcionario designado (Art. 24). La investigación y su dictamen se elevaban a la inspección Seccional para el estudio y propuesta de la medida disciplinaria (Art. 25). La Inspección Seccional pasaba el expediente a la Inspección General para el pronunciamiento y resolución de la causa (Art. 26).

${ }^{4} \mathrm{La}$ "conducta delictuosa, desarreglada o inmoral" era causante de una investigación sumarial. Véase, Argentina. Consejo Nacional de Educación (1925). "De sus causas y clasificación", en Reglamento de Sumarios. Talleres gráficos del Consejo Nacional de Educación.
} 
En el análisis de las evidencias se utiliza la perspectiva de género, concepto útil para "pensar de manera crítica sobre cómo los significados de los cuerpos sexuados se producen en relación el uno con el otro, y cómo estos significados se despliegan y cambian" (Scott, 2016: 98). En ese sentido, consideramos que reconstruir cómo fueron narradas las experiencias de las mujeres maestras por ellas y por sus contemporáneos, aporta historicidad a las operaciones que desde el discurso público relacionaron el cuerpo femenino con los atributos propios de "la madre".

En la pluralidad de las maneras de actuar de las maestras se descubre el sentido y los límites del control social, en palabras de Arlette Farge (1991), las "conductas femeninas razonadas, pactando o no con otras conductas, masculinas, y cuyo razonamiento se apoya, entre otras, en ciertas formas de apropiación del poder" (34). Al respecto, nos interesa más que detectar las definiciones moralizantes y normativistas, pensar cómo se confrontaron o reivindicaron en una comunidad, las concepciones sobre determinadas dimensiones constitutivas del ejercicio de la profesión.

En una escuela primaria de Buenos Aires, vecinos y vecinas acusaron a una docente por un comportamiento que "habla muy poco en favor de la cultura que deben tener las maestras a quienes se les confían nuestros hijos, y que en todo momento deben comportarse como una segunda madre y no como verdugo de los mismos". ${ }^{5}$ En Misiones, cuestionaron el "agravante de la altivez, de la soberbia y hasta la falta de verdadera grandeza moral de que [sic] debe estar revestido todo maestro", 6 en Río Negro, el "poco cariño por su profesión". ${ }^{7}$ En Salta, los padres reclamaron porque una maestra se desató con improperios "ante todos los alumnos presentes, empleando palabras que sería vergonzozo [sic] transcribirlas", 8 en varias escuelas fueron denunciados maltratos y burlas ${ }^{9}$ hacia niños y niñas. En la muestra analizada se observa un marcado desbalance en el género de los acusados y las acusadas, la mayor parte de las denuncias se realizaron contra docentes mujeres. ${ }^{10}$

\footnotetext{
${ }^{5}$ AIN. CNE, expediente núm. 17.592, Buenos Aires, 1948.

${ }^{6}$ AIN. CNE, expediente núm. 12.909, Misiones, 1948.

${ }^{7}$ AIN. CNE, expediente núm. 1.083, Río Negro, 1948.

${ }^{8}$ AIN. CNE, expediente núm. 13.107, Salta, 1948.

9 AIN. CNE, expediente núm. 16.206, Jujuy, 1948 y expediente núm. 24.960, Buenos Aires, 1948.

${ }^{10}$ Las acusaciones contra los varones, maestros y directores, estuvieron centradas en su actuación en los lugares de esparcimiento, despachos de bebidas o casas de juego, y en el trato o vocabulario impropio hacia las familias. Para el contenido de los expedientes véase, entre otros, AIN. CNE, expediente núm. 17.869, Tucumán, 1948; expediente núm. 18.125, Santiago del Estero, 1948; expediente núm. 21.482, San Luis, 1948; expediente núm. 22.353, Corrientes, 1948. En este trabajo se han tomado los expedientes con denuncias hacia las maestras mujeres.
} 
Entre los documentos que cuestionan los mandatos sobre la moralidad de las acciones de los maestros y las maestras, hallamos uno que se diferencia de los demás, el expediente núm. 10.705 de Río Negro. Su contenido tiene puntos en común con sumarios analizados en recientes investigaciones realizadas por Paula Caldo (2019) y Adrián Cammarota (2020). Estos trabajos examinan denuncias efectuadas durante la primera década del siglo $\mathrm{XX}$, en las escuelas de los Territorios Nacionales, que culminaron en la separación o alejamiento de los o las docentes del cargo. Las sanciones o exoneraciones habían sido motivadas por supuestas infracciones morales cometidas por hacer públicos aspectos de la vida privada. En ambas pesquisas observamos dos figuras dicotómicas, el varón fuerte, engañado por la maestra "perversa" o de "baja moral"; y la mujer débil, culposa, ingenua e inocente. La trama del expediente núm. 10.705 expone una actitud similar en los varones, pero invita a reflexionar sobre una cuestión que aún no ha sido trabajada en profundidad, aquellas mujeres jóvenes que rompieron con la visión de la escuela como espacio neutro de poder y tensionaron con sus gestos, palabras y actitudes, los sentidos y significados del "deber ser" asignados para ellas por el Estado. ${ }^{11}$

\section{El conflicto: denunciantes denunciadas}

Al cerrar el ciclo lectivo de 1946, las maestras H., SM. y L. de la escuela primaria nacional de un poblado patagónico, se presentaron en la sede de la Inspección Seccional Sexta de Viedma, Río Negro, para exponer un reclamo en contra del director, solicitaban la rectificación del "injusto concepto" profesional que habían recibido. Luego de la exposición colectiva escribieron las notas de descargo en forma individual. H. y SM. no aceptaban la calificación "regular" para el desempeño y "relativa" para la conducta, L. había recibido una buena calificación pero decidió acompañarlas. Según el Digesto si después de notificado, el maestro no estaba de acuerdo con la crítica realizada por el director, podía presentar sus observaciones en la forma pertinente debiendo darse intervención al Inspector Técnico inmediato. ${ }^{12}$

\footnotetext{
${ }^{11}$ AIN. CNE, expediente núm. 10.705, Río Negro, 1948. En adelante, los testimonios de los inspectores, del director, de las maestras y de los testigos entrevistados pertenecen a este expediente. Por tratarse de información sensible, para las tres maestras protagonistas, el director y los funcionarios no se utilizan sus nombres verdaderos.

${ }^{12}$ Argentina. Consejo Nacional de Educación. (1937). Digesto de Instrucción Primaria, Buenos Aires: Talleres gráficos del Consejo Nacional de Educación, p. 385. El Digesto continuó vigente durante la década del cuarenta y del cincuenta. Sobre el contenido de las normas y regulaciones que conformaron los digestos véase Marengo (2019: 77-78).
} 
H. y SM. formularon idénticos cargos. En la nota escrita dirigida al Inspector I. M. una de ellas argumentó su denuncia:

“1) Mi capacidad profesional ha merecido la calificación de escasa [... 2) Mi reputación ha sido considerada por el Director de "regular", aún cuando mis actos han sido correctos y morales pudiendo dar fe de ello el vecindario. 3) Mi aliño, cortesía y adhesión al trabajo han sido calificados igualmente de escasos, no existiendo causa justificada para ello, desde el momento que siempre he asistido a la escuela correctamente vestida, 4) de la misma manera ha sido juzgada mi educación".

En el último párrafo agregó: “En varias oportunidades he sido tratada en forma grosera [...] De la misma manera he sido molestada varias veces por insinuaciones al margen de toda moral."

Cuando fueron citadas para ratificar la denuncia, la señorita H. reiteró que el director "en el aula y en la dirección, le hizo insinuaciones, primero veladas y después más directas, de carácter amoroso lo que la instaron a solicitar el traslado inmediato, para terminar con esa situación violenta e inaceptable", SM. no se presentó, y L. mantuvo su firma y argumentó: "en varias oportunidades he sido tratada en forma desconsiderada [...] a los gritos [...] en forma brusca y sin respeto". Según el artículo 2 inciso 5 de las medidas disciplinarias establecidas en el Digesto, "los actos contrarios a la moral y buenas costumbres y los vicios deprimentes", ${ }^{13}$ eran considerados una falta grave, por lo tanto la Inspección debía comenzar la investigación sumarial. ${ }^{14}$

\section{"Con la corrección que corresponde a educadoras": implicancias del deber ser en ejercicio de la docencia}

En paralelo a la consolidación del Estado argentino, las características biológicas, hombre-mujer, establecieron los parámetros de ocupación del espacio público. La mujer fue considerada incapaz, sumisa, subordinada al padre y luego al marido, por lo tanto, marginada del mercado laboral, al servicio de la reproducción y de los quehaceres domésticos. Durante la primera mitad del siglo XX, lejos de atender la soberanía de los sujetos, estas concepciones se plasmaron en órdenes que combinaron la moral sexual y la naturaleza. Resultaba moralmente inaceptable que ellas se desempeñaran en la

\footnotetext{
${ }^{13}$ Argentina, Consejo Nacional de Educación. (1937). Digesto de Instrucción Primaria, Buenos Aires: Talleres gráficos del Consejo Nacional de Educación.

${ }^{14}$ Para la actuación de los inspectores del CNE en la ejecución de sumarios véase Fiorucci (2013) y Cammarota (2020).
} 
vida pública porque la "norma natural" consistía en ocuparse del hogar, casarse y engendrar hijos (Barrancos, 2000). Por esos años, y ante la imperiosa necesidad de educar al ciudadano, el Estado legitimó el trabajo de la mujer en una función para la cual estaba considerada biológicamente apta, el magisterio. La mujer era la única que poseía las cualidades maternales, contrapuestas a las masculinas, capaz de prolongar la labor privada al espacio público para cumplir con la tarea de enseñar y amar a los hijos de la nación (Lionetti, 2007; Morgade, 1997).

La formación normalista suponía una cierta transmisión de valores y actitudes basados en el orden, la disciplina, la higiene, el amor por el saber y la moralidad de las costumbres. La distribución de rasgos y características diferenciales y desiguales a varones y a mujeres, sustentado en un discurso pedagógico disciplinador de matriz heterosexual y sexista, legitimó un orden corporal escolar generizado a partir de la delimitación de reglas, prácticas y saberes. Al interior de las escuelas, el Estado autorizó posiciones, gestos, desplazamientos, movimientos y miradas que constituyeron "universos morales precisos como la modestia o el recato" (Scharagrodsky, 2007: 5). De este modo, se configuró en el sistema escolar "un engranaje de apariencias traslúcido en la estética escolar, la producción de materiales instructivos con formatos y lenguajes específicos, códigos de vestimentas y conductas naturalizadas como correctas" (Cammarota, 2020: 417). Maestros y maestras, debían "ser y parecer".

El modelo ideal no evitó, sin embargo, que se desplegara una multiplicidad de actitudes y comportamientos ajenos al modelo del "buen educador" (Varela, 2009: 345). Las acusaciones que constan en el expediente núm. 10.705 de Río Negro expresan la fuerza coercitiva que había adquirido la construcción normativa de la figura pública femenina y dan "indicios de la construcción de lo considerado femenino y de las resistencias que efectivamente y contra las adversidades, muchas mujeres del pasado realizaron contra sus condiciones de existencia" (Acha y Halperin, 2001: 24).

\section{La versión del director}

Teniendo en cuenta los contextos culturales locales y regionales de la Argentina, las prácticas discursivas estatales relacionadas con el rol, presencia y actitud de los maestros y las maestras, se tiñeron de las diferentes concepciones lugareñas y de la impronta que fue tomando el crecimiento del sistema educativo en cada lugar. A mediados de la década del cuarenta, en las escuelas de los Territorios, el magisterio se había constituido en una profesión para 
mujeres, sin embargo, "su accionar no había sido definido ni concebido como trabajo" (Billorou, 2015: 6). La docencia era considerada como la prolongación de las tareas maternales hacia la sociedad. Esas ideas, representaciones y opiniones, que imaginaban un ideal de conducta moral intachable y presencia impecable, fueron los parámetros que utilizó el director para expresar las falencias de las jóvenes y defenderse de las acusaciones.

Al igual que en el caso analizado por Cammarota (2020), sumó a la acusación de inmoralidad, las deficiencias técnicas de las maestras. En el expediente núm. 10.705 de Río Negro, uno de los argumentos consistió en mostrarlas como irresponsables e incapaces en las tareas administrativas. La prueba estaba en los registros mal confeccionados, la suma de las inasistencias y las llegadas tarde. Según consta en la investigación realizada por el inspector, en 1946, la señorita $H$. había registrado 4 días de licencia, 19 insistencias y 49 llegadas tarde, L. tenía computadas 22 inasistencias y 30 llegadas tarde, y SM. 29 días de licencia por enfermedad, 22 inasistencias y 35 faltas de puntualidad.

La defensa del director se completa con un relato sobre las acciones y las palabras con las que las mujeres transgredían el estereotipo "maternal". El acento estaba puesto en las actitudes de H. y S.M., su escasa cortesía, la participación en grescas, la escasa pulcritud de sus aulas y el trato violento hacia los alumnos. El "persistente espíritu de rebeldía" y la ausencia de "la más estricta buena conducta" quedaba demostrado en un acontecimiento particular. Según la versión del hombre, en ocasión de festejar junto al alumnado y las familias vecinas el día de la primavera, las tres maestras habían llevado un aparato musical y en un momento dado, la señorita $H$. había pedido tocar la canción "El Caimán", "cuya letra procaz de un sentido francamente indecente" no podía ser oída por los niños de la escuela.

Lo disruptivo de esta escena fue la respuesta que recibió el hombre. En las disputas que relata Cammarota (2020), la maestra reclamaba por su honor y pedía justicia; en los testimonios que analiza Caldo (2019), la señorita "se asume como la joven ingenua abusada por el varón dominador". En el caso que aquí hallamos se reconocen otras voces que escapan del modelo predominante. Consta en actas que la mujer que protagonizó la experiencia contestó: "Con este viejo de [...] no se puede" y cuando fue indagada por el inspector, explicó que su falta fue "haber bailado en forma moderna, malinterpretada por el criterio un tanto estrecho del citado director".

El último cuestionamiento recayó sobre la vestimenta inapropiada de $\mathrm{H}$. característica que determinó la "relativa reputación" designada en la foja de concepto que inició el reclamo original. Según el director: 
“...la indumentaria diaria de la citada docente, señorita [H.], no es la más conveniente para desempeñarse en la noble misión que se le ha confiado. Su vestido, de una exigüidad rayana en la escasez del paño, se presenta en una forma exageradamente corta, acompañado de un calzado de taco pronunciadamente alto, presentando una persona que dista mucho de la madre sencilla, pulcra y seria que los niños tienen derecho [a ver] reemplazada en su maestra, que revele pudor y austeridad".

Según el relato completo, la situación no era nueva, $H$. se había presentado delante de los alumnos sin el guardapolvo en varias ocasiones y en una de las reprimendas, "contestó que no lo llevaba puesto porque la lavandera no se lo había preparado y alguna vez, que no sabía que era obligatorio". Como señalan Lionetti y Varela (2008), la maestra de ninguna manera podía mostrarse frívola y hacer demostraciones de ostentación en su aspecto exterior. Para que respetaran, estimaran y valoraran sus funciones, el perfil esperado para la docente estaba revestido de rasgos asexuados. “Debían estar siempre atentas puesto que la población no permanecía ajena al desempeño profesional y moral de las educadoras de sus hijos" (225-226). En este caso, la vestimenta era una prueba fehaciente del comportamiento y eje central de la intervención estatal (Ben, 2001: 65). La sagrada maestra, como la madre, no podía ser pensada como sujeto de deseo sexual.

\section{La versión de los vecinos y de las autoridades}

Durante los años cuarenta se produjo la irrupción masiva de las mujeres en el mundo público, sin embargo, el avance en la participación ciudadana no modificó la interpretación social de su rol de guardiana del hogar y de la familia (Franco y Pulido, 1997). Desde el Estado, los hombres continuaron redactando regulaciones sobre su cuerpo, su sexualidad, su uso y su destino (Di Liscia y Rodríguez, 2004). El aumento en las cifras de trabajo femenino no modificó las profesiones y oficios tradicionalmente legitimados, enfermeras, asistentes sociales y maestras continuaron siendo la extensión pública del cuidado y el amor maternal.

En la Patagonia, el discurso del Estado basado en concepciones morales que asignaban a la mujer determinados roles predefinidos, fue acompañado por el mensaje católico desplegado por las misiones religiosas. Desde principios del siglo $\mathrm{XX}$, en los territorios nacionales del sur se habían conformado dos sistemas educativos, el estatal representado por los vecinos caracterizados, el ejército y las autoridades centrales, y el confesional católico fundado por la 
Congregación Salesiana, Salesianos e Hijas de María Auxiliadora, con presencia desde Viedma y Carmen de Patagones hasta Tierra del Fuego. Los estudios especializados coinciden en señalar que la implementación de la Ley 1.420 de educación común había encontrado dificultades y resistencias, entre ellas, la distancia con el gobierno central y la dispersión de la población. Signado por la conveniencia económica que significaba el desarrollo de la obra misionera de los Salesianos, el Estado los dejó crecer. Así, la Congregación acrecentó el despliegue de la propaganda de la fe cristiana y la moralidad en las costumbres públicas y privadas (Nicoletti, 2016; Zaidenwerg, 2013; Teobaldo y García, 2000). Ese contexto echa luz sobre las recomendaciones hacia las maestras que un inspector redactó en un acta de reunión escolar:

"Cuatro de las cinco maestras inician recién su carrera profesional, por cuyo motivo deben consagrarse por completo, tesoneramente [...] en el trabajo, en el aula y en el medio, actuar con tino, cordura y honestidad que corresponde al delicado apostolado, máxime teniendo en cuenta el ambiente no muy comprensivo para juzgar tolerantemente hábitos y costumbres que se apartan de las modalidades lugareñas".

Las mujeres que acusaron el director estaban en un espacio controlado y regulado por normas que, a la vez, brindaban la posibilidad de un desempeño profesional y un empleo remunerado, sin el control familiar. El dato sobre la escasa antigüedad no es menor porque introduce en el análisis la variable generacional. El inicio laboral de las docentes en las escuelas de los Territorios implicaba el traslado de sus lugares de origen a pequeñas localidades del interior o escuelas rurales. Alejadas de la familia, situación impensable para las mujeres según los cánones morales de la época, tomaban contacto con una nueva red de relaciones sociales formada por la comunidad educativa que las recibía y los nuevos compañeros y compañeras de trabajo (Billorou, 2016: 67).

En los Territorios, las escuelas y los docentes cumplían funciones pedagógicas y sociales, enseñaban el idioma, la lectura, escritura y contenidos vinculados con la argentinización, pero también intervenían en cuestiones de la comunidad, eran considerados una voz autorizada y compartían con los habitantes del pueblo sus intereses y preocupaciones (Nicoletti y Méndez, 2018). Esos actores locales ocuparon un rol primordial cuando fueron citados para colaborar con la investigación.

El inspector indagó a los vecinos, autoridades del pueblo y a dos miembros del personal de la escuela cercana, sin mencionar la acusación de las tres mujeres hacia el director. Por el contrario, invisibilizadas las declaraciones de las maestras, la pregunta que escucharon los testigos fue: "si, como vecino de 
este pueblo, ha podido observar la conducta de las maestras Srta. [...] y si se han comportado, a su juicio, como corresponde a educadoras".

En una de las declaraciones puede leerse, "salvo los casos de concurrir a bailes y hacerlos siempre en forma un tanto exagerada, especialmente una de las maestras a quien vio muy alegre bajo los efectos del alcohol [...] no ha podido observar otra cosa". Otro vecino indicó que pudo comprobar "reiteradamente" un comportamiento que no era propio de maestras de escuela "por la excesiva confianza que dispensaban a los jóvenes y por la liberalidad y exageración en sus diversiones". Otro expresó que había podido observarlas

“...en fiestas y bailes desempeñándose en forma grosera $\mathrm{y}$ excesivamente llamativa, dando un ejemplo poco digno al vecindario como educacionistas [...] que en una oportunidad, en un pic-nic escolar pusieron un disco para bailar (El Caimán) que tiene una letra inapropiada"

Uno de los testigos, miembro de la Cooperadora declaró que a su juicio,

“...la conducta observada en esas señoritas ha dejado mucho que desear ya que se han comportado en todos los actos sociales, bailes, fiestas y paseos en forma exagerada, llamando siempre la atención y dando mal ejemplo. Que el año pasado tenían pensión en su casa y que, en varias oportunidades, debió llamarles la atención a fin de evitar el mal ejemplo a su familia y velando por el buen nombre del hotel".

Entre las autoridades las declaraciones fueron diferentes. El subcomisario de la comisaría del pueblo señaló que "nada puede objetar [del comportamiento de H. y L.] pues siempre se les ha visto conducirse con corrección y respeto", pero la señorita SM. "ha dejado mucho que desear, particularmente cuando intervenía en bailes públicos, oportunidad en que bebía con exceso, según podía observarse fácilmente”. En el informe final el inspector dudó de la palabra citada y argumentó: “¿es posible concebir una diversidad de proceder de ambas maestras [H. y SM.] en circunstancias iguales, mientras en lo general aparecen obrando armónicamente? Creo que el subcomisario ha sido bondadoso con una".

Uno de los representantes de la Sociedad de Fomento declaró que tenía el mejor de los conceptos, el Juez de Paz expresó que se habían comportado con corrección y respeto, y el Jefe de Correos declaró que

“...las maestras me merecen buen concepto [...] Creo al mismo tiempo agregar, que para el buen nombre de ellas y prestigio del Magisterio, es de recomendarles atento al lugar en que están 
actuando, que adopten una vida más recatada y cautelosa para evitar así comentarios desfavorables en pugna con la misión que se les ha confiado".

En el expediente núm. 10.705, Río Negro, del total de 33 testigos, 13 observaron que H., SM. y L., "principalmente las dos primeras", no se habían conducido en bailes y fiestas "con la corrección que corresponde a educadoras, ya que bailaban siempre en forma exagerada y llamativa dando lugar a críticas y censuras en el vecindario", 4 declararon que la señorita SM. bebía con exceso en bailes y fiestas, 14 testigos, y de ellos solo 2 mujeres, expresaron que las maestras se habían comportando correctamente.

En la última instancia del trámite, el Inspector de Región señaló con elocuencia: "es lamentable que en un asunto de tanta importancia, no se consultó al personal docente de la escuela". La ausencia arbitraria brinda indicios sobre la mirada punitivista del inspector, a excepción de las tres mujeres acusadas, no citó al personal femenino, desestimó la acusación original y puso en duda la "decencia" de las maestras, no del director. En 1949, el expediente pasó a manos del delegado interventor del CNE, máxima autoridad de la burocracia estatal. Las medidas tomadas fueron "apercibir severamente" a H., quién había logrado el traslado a Buenos Aires, "llamar la atención" a SM., quien siguió en la docencia pero no volvió a presentarse en la escuela del pueblo rionegrino, y "advertir" a L. para que no vuelva a entrometerse en esos problemas. $^{15}$

Como señalan Eva Muzzopappa y Carla Villalta (2011), en las prácticas discursivas que el Estado impuso, a través de informes, reglamentos, resoluciones o disposiciones internas, aparece en primer plano el "deber ser" de la institución y sus agentes, su autoimagen y los objetivos institucionales explícitos. Como se ha visto, las denuncias y los argumentos que componen los sumarios se convierten en evidencias del reverso del discurso pedagógico normalista, heteronormado y disciplinador

“...no en relación con el grado de cumplimiento que con ellas alcanzaron los objetivos que supuestamente las motivaron, sino respecto de por qué tales objetivos fueron formulados, cuáles habían sido las cuestiones, temas o comportamientos que previamente se habían definido como problemáticos y que condujeron a su enunciación" (32).

\footnotetext{
${ }^{15}$ En el capítulo sobre los sumarios, el Digesto establecía que las faltas leves eran reprimibles con apercibimiento, suspensión o multa y las graves con cesantía, destitución o exoneración (Art. 26).
} 
De este modo, la variable generacional en un contexto socio político en transformación, podía transformarse en nuevo nudo problemático a desentrañar. La aceptación o transgresión de las posturas conservadoras que conformaban el "ser y parecer" expresaban los cambios y permanencias al interior de cada comunidad y del sistema educacional.

\section{A modo de cierre}

Las actitudes y expresiones verbales de las jóvenes mujeres que protagonizaron el conflicto que dio origen al expediente núm. 10.705 de Río Negro, pusieron en cuestión las prácticas disciplinadoras producidas y naturalizadas por el discurso escolar. En este caso, la imagen maternal, pura y dulce de "la maestra" que primó en el orden pedagógico tradicional, heteronormativo y patriarcal, no silenció la aparición de "otras" mujeres, rebeldes, contestadoras y desprejuiciadas que integraron las filas del sistema educativo nacional.

Sabemos que las declaraciones testimoniales que aquí conocimos no expresan la versión real de los hechos, porque el archivo "los saca de su vida cotidiana, los fija en algunas reclamaciones o en algunas lamentables negativas" (Farge, 1991: 25), sin embargo, el contenido expone las estructuras de poder heteropatriarcal de la época. En ese sentido, la oscilación entre la norma y la desviación que se observa en las evidencias demuestra la permeabilidad de los modelos normativos moralistas y, a su vez, los límites identitarios del concepto "magisterio".

Más allá de las repercusiones o consecuencias en el entorno social o en la trayectoria laboral de cada una, los conflictos que describen los expedientes iluminan problemáticas que nos invitan a continuar interrogando acerca de las nuevas generaciones de docentes que, con diferentes estrategias e intereses, plantearon resistencias a los mecanismos de control de la sociedad a la que pertenecieron

Ciudad de Buenos Aires, diciembre de 2020

\section{Referencias bibliográficas}

Acha, O. y Halperin, P. (2001). Cuerpos, géneros e identidades. Estudios de historia de género en Argentina. Ediciones del Signo.

Alvarado, M. (2017). El Alegato de Florencia Fossatti: claves para una historia de las ideas pedagógicas desde una epistemología feminista, Historia de la Educación. Anuario, (2), 104-119. [en línea] http://ppct.caicyt.gov.ar/index.php/anuario/article/view/9460 
Barrancos, D. (2000). Moral sexual, sexualidad y mujeres trabajadoras en el período de entreguerras. En F. Devoto y M. Madero (Dirs.), Historia de la vida privada en la Argentina, (pp. 199-226). Taurus.

Becerra, M. (2019). Un cuarto propio: relaciones de género, amor y magisterio en la Argentina de inicios del siglo XX. Propuesta Educativa, (51), 42-60. [en línea] http://propuestaeducativa.flacso.org.ar/wpcontent/uploads/2019/11/PropuestaEducativa51-dossier-BECERRA.pdf

Ben, P. (2001). Muéstrame tus genitales y te diré quién eres... En O. Acha y P. Halperin Cuerpos, géneros e identidades. Estudios de historia de género en Argentina. Ediciones del Signo.

Billorou, M. (2015). Mujeres que trabajan. Las maestras pampeanas en la primera mitad del siglo XX. Anuario Facultad de Ciencias Humanas, (12), 1-18 [en línea] http://dx.doi.org/10.19137/an1201 - ISSN 2314-398

Billorou, M. (2016). Mujeres que enseñan no solo en las aulas: docentes en el interior argentino en la primera mitad del siglo XX. Historia de la Educación. $\begin{array}{lllll}\text { Anuario, } & 17 & (2), & 57-79 . & \text { [en }\end{array}$ http://ppct.caicyt.gov.ar/index.php/anuario/article/view/9793

Caldo, P. (2019). Entre amores clandestinos y cesantías. La maestra y el director, Argentina, 1920-1928. Géneros, (26), 145-163. [en línea] http://revistasacademicas.ucol.mx/index.php/generos/article/view/1694

Caldo, P. y Fernández, S. (2010). Biografía, historia y mujeres: la revisión de un vínculo complejo a partir del caso de Olga Cossettini, 1898-1987. Avances del Cesor, (7), 115-139. [en línea] http://biblat.unam.mx/hevila/AvancesdelCESOR/2010/no7/7.pdf

Cammarota, A. (2020). Relatos sobre maestras acosadas e inmorales: género, educación y disciplinamiento en el sistema escolar argentino (1919-1935). Historia y Memoria de la Educación, (12), 395-432. [en línea] http://revistas.uned.es/index.php/HMe/article/view/25901/21521

Di Liscia, M. y Rodríguez, A. (2004). El cuerpo de la mujer en el marco del Estado de Bienestar en la Argentina. La legislación peronista (1946-1955). Boletín Americanista, (54), 63-85. [en línea] https://dialnet.unirioja.es/descarga/articulo/1256358.pdf

Farge, A. (1991). La atracción del archivo. Edicions Alfons el Magnanim.

Fiorucci, F. (2013). La denuncia bajo el peronismo: El caso del campo escolar. Latin American Research Review, 48 (1), 3-23. [en línea] https://www.researchgate.net/publication/262093835_La_denuncia_bajo_el_per onismo_El_caso_del_campo_escolar 
Franco, M. y Pulido, N. (1997). ¿Capitanas o guardianas del hogar? Deseos y mandatos en la Argentina Peronista. Boletín americanista, (47), 113-126. [en línea] https://www.raco.cat/index.php/BoletinAmericanista/article/view/98671

Lionetti, L. (2007). La misión política de la escuela pública: educar al ciudadano de la república (1870-1916). Miño y Dávila.

Lionetti, L. y Varela, P. (2008). Las instituciones escolares: escenarios de conflictos, crisis de autoridad y trasgresión a la norma (1882-1940). En D. Miguez (Comp.), Violencias y conflictos en las escuelas. Paidós.

Marengo, R. (2019). Digestos. En F. Fiorucci y J. Bustamante Vismara (Comps.), Palabras clave en la historia de la educación argentina. UNIPE.

Méndez, L. y Zampa, S. (2019). Blancas palomitas y segundas mamás. Ponderaciones sobre maestras y alumnas en la Norpatagonia de la primera mitad del siglo XX. La Aljaba. Segunda Época. Revista de Estudios de la Mujer, (23). [en línea] https://doi.org/10.19137/aljaba-2019-230106

Morgade, G. (1997). Mujeres en la educación. Género y docencia en la Argentina. Miño y Dávila.

Muzzopappa, E. y Villalta, C. (2011). Los documentos como campo. Reflexiones teórico-metodológicas sobre un enfoque etnográfico de archivos y documentos estatales. Revista Colombiana de Antropología, 1, (47), 13-42. [en línea] https://www.aacademica.org/carla.villalta/5.pdf

Nicoletti, M. (2016). Formar ciudadanos argentinos y católicos en la Patagonia Norte de los territorios nacionales: la Congregación Salesiana y las escuelas del Estado (1880-1950). Boletín Americanista, (72). [en línea] https://revistes.ub.edu/index.php/BoletinAmericanista/article/view/16059/19097

Nicoletti, M. y Méndez, L. (2018). Progresos de la Educación en la República Argentina y Chile: Escuelas e Iglesias para los vecinos de Bariloche en las primeras décadas del siglo XX. Historia de la Educación. Anuario, 19 (1), 50-65. [en línea] http://ppct.caicyt.gov.ar/index.php/anuario/article/view/14243

Scharagrodsky, P. (2007). Masculinidades valuadas y devaluadas. Tensiones, límites y posibilidades en el ámbito escolar. En R. Baquero; G. Frigerio y G. Diker Las formas de lo escolar. Del Estante.

Scott, J. (2008). Género e Historia. Fondo de Cultura Económica.

Scott, J. (2016). Género: ¿Todavía una categoría útil para el análisis? La Manzana de la Discordia, 6 (1), 95-101. 
Teobaldo, M. (2008). Las luces de la civilización enseñar y aprender en las escuelas de la Patagonia norte. Neuquén y Río Negro (1884-1957). Espacios en Blanco. Revista de Educación, (18), 167-186.

Varela, P. (2009). Consideraciones sobre la 'escuela real': instituciones de formación docente en Argentina, provincia de Buenos Aires, 1930-1943. Revista mexicana de investigación educativa, 12 (41), 343-374. [en línea] http://www.scielo.org.mx/scielo.php?script=sci_arttext\&pid=S140566662009000 200002\&lng=es\&tlng=es

Yannoulas, S. (1996). Educar: ¿una profesión de mujeres? La feminización del normalismo y la docencia 1870-1930. Kapelusz.

Zaidenwerg, C. (2013). 'Amar, honrar y servir a la patria'. Las escuelas del Territorio Rionegrino y su aporte a la obra argentinizadora en el Sur (19081930). Páginas, revista digital de la Escuela de Historia, 5 (9), 61-89. [en línea] http://web.rosario-

conicet.gov.ar/ojs/index.php/RevPaginas/article/view/260/308 